\title{
Role Expansion: Implications of the Security Role Expanding into the EHS Function
}

\author{
Wanda D. Minnick, Jonathan D. Cunkelman \\ Safety Sciences Department, Indiana University of Pennsylvania, Indiana, USA \\ Email: wanda.minnick@iup.edu, J.D.Cunkelman@live.iup.edu
}

Received 10 July 2015; accepted 17 August 2015; published 20 August 2015

Copyright (C) 2015 by authors and Scientific Research Publishing Inc.

This work is licensed under the Creative Commons Attribution International License (CC BY). http://creativecommons.org/licenses/by/4.0/

(c) (i) Open Access

\section{Abstract}

The purpose of this study was to explore the perception of safety professionals regarding the expansion of their role into security functions. One hundred eleven returned surveys from practicing safety professionals in the manufacturing, oil and gas, and construction industries were examined. Fifty seven percent of respondents agree with role expansion into security and twenty three percent of participants do not. Thematic patterns emerged from their comments and are provided. The remaining twenty percent of respondents fell into a category of "it depends" and the provided reasons suggest other variables that could have influence. A Chi square test for independence indicated that role expansion is independent of industry type; suggesting there is agreement for role expansion into security functions regardless of industry type. Another primary finding is that although the majority of safety professionals agree with role expansion, security coursework is currently not required in a review of accredited occupational safety and health program curricula. This suggests recent graduates may not be formerly prepared for the security elements of their role and should seek or be offered additional training.

\section{Keywords}

Role Expansion, Safety Professional, Security, Role Overload

\section{Introduction}

The role of the safety professional can be defined as a person that engages in the recognition of hazards, the evaluation of risk, and provider of guidance and counsel on controlling or minimizing risk. The American National Standard Institute (ANSI), an organization that promulgates guidelines used in various business sectors, along with the American Society of Safety Engineers (ASSE) defines the scope and function of the professional safety position in guideline ANSI/ASSE Z590.2-2003 and is described on the ASSE body of knowledge website. 
The primary tenets of the role being to identify, evaluate, and develop hazard controls. In addition the role includes warning and advising others in prevention strategies and overall risk reduction as well as measuring and auditing effectiveness of hazard controls [1]. The Board of Certified Safety Professionals further defines today's safety role as identifying what hazardous events can occur and the likelihood of that occurrence, the severity of the results, the overall risk (a combination of probability and severity), and cost [2]. In comparison, the American Society for Industrial Security (ASIS) defines the term security and describes an overall scope for the security function. It notes that security is a similar concept to safety with one clear distinction; within security added emphasis is placed on dangers originating from the outside [3]. ASIS also explains that the term security means that something is not only secure but it has been secured. The scope of the security function is to reduce the risk of unintentionally and naturally-caused crises and disasters that disrupt and have consequences on the products and services, operation, critical assets, and continuity of the organization and its stakeholders [4].

Many identify safety and security as two separate fields, but recent research has indicated that the safety professional's role is beginning to expand to include security functions. Specifically $25 \%$ of safety professionals from the manufacturing industry indicated they currently have security roles within their job function [5].Within that study, those that indicated the word "security" as a job descriptor explained their roles in some of the following ways: the development of security plans, conducting facility vulnerability assessments, being a member of the crisis team, designing and implementing various security systems to reduce vulnerabilities, working with classified documents and conducting personnel training in security awareness. Consideration of how the two disciplines were formed provides a foundation in which to examine the similarities and the potential merging of the two roles.

\section{History of the Safety and Security Disciplines}

The ASSE was found in 1911 and currently has 36,000 members. It is the oldest professional safety society and is committed to protecting people, property and the environment [6]. Hence, from the very beginning organized safety professionals have played a role in security. The American Society for Industrial Security (ASIS) was founded in 1955 and has over 38,000 members, each of whom has a role in the protection of assets-people, property, and/or information. It is currently known as ASIS international and has 234 worldwide chapters [4].

Both safety and security have relied on tremendous tragedy to bring about legislation that requires industry and others to maintain minimum standards. The triangle shirtwaist factory, BP in Texas and the Union Carbide plant in Bhopal, India are some of the tragic examples that led to legislation in safety. Likewise, the increased attention following the first World Trade Center attack in 1993 (truck Bomb), attacks on several US embassies and overseas military installations, as well as the events of 9/11/2001 heightened the awareness for the value of the security function. Another similarity exists in the reporting structure of each discipline, typically both functions reporting directly to upper management. In addition, both disciplines have the very difficult task of proving to management that their plans and actions are effective; meaning it can be hard to prove the loss you have prevented.

Safety and security professionals have a common goal of wanting to protect people and property, therefore it is important that their efforts, plans, and policies work together. Safety and security should have an understanding and knowledge about what the other is doing, as the very barriers designed to protect the employees from a security standpoint could also create a hazard. For example, the locks and doors that are installed to prevent unauthorized entry can fail or be misused and trap personnel and prevent evacuation in an emergency situation. Vehicle access barriers designed to prevent potential truck bombs from entering a facility could prevent emergency responders from timely access.

\section{Justification}

A recent study of safety professionals in the manufacturing industry asked participants to describe the functions within their role. The intent of this study was to consider the number of roles in which safety professionals are engaged and if an increase in roles correlated with an increase in role conflict, a precursor to negative job states. Of the 356 qualitative responses, 25\% $(N=88)$ participants listed the word "security" when providing a description of their role [5]. This finding suggests a growth trend (or baseline to mark potential growth) into security functions. In the same aforementioned study, it was concluded that as the number of roles increases so does the average role conflict score (a measure of job stress). Specifically, there was a significant difference in the aver- 
age role conflict score by number of roles group membership $(F=2.69, d f=5411, p=0.021)$, suggesting that further expansion of the safety professional's role (into security) could contribute to role overload. Brown, Jones and Leigh [7] explain that role overload is experienced "when role demands create the perception that available resources are inadequate to deal with them, resulting in distraction and stress” (p. 972). This purpose of this study is to explore the safety professional's perception of role expansion into the security function to discern not only if a study on role overload is warranted but also if role expansion into the security function is welcomed by safety professionals.

\section{Method}

Data for this study was obtained from administering an on-line survey to members of the American Society of Safety Engineers (ASSE), specifically members of the three largest practice specialty groups. To be included in this random sample, the following conditions had to be met: be a member of an academic specialty in the manufacturing, oil and gas, or construction industry and be employed as a safety professional; not be retired, not be employed as a full-time consultant, and not be employed as a full-time trainer. Justification for inclusion criteria was to limit participation to those members engrained in the daily operations of their company and those with an elevated expertise in a particular industry, as indicated by their membership in a specialty practice group. In addition, only those participants that answered the open-ended questions regarding role expansion were included, resulting in 111 applicable returned surveys. The survey instrument consisted of the following two questions: 1) Do you agree with the expansion of the safety role into security functions?: Yes or No and 2) describe why you do or why you do not agree with the expansion. An inductive approach was used in coding the qualitative data and enabled the identification of over-arching categories in which the reasons for agreement or disagreement could be sorted. Descriptive information considered in this study included industry type. Chi square test for independence was conducted to test the hypotheses below. If the $p$ value was $<0.05$, an association existed between the variables.

$H o=$ role expansion agreement is independent of industry type.

$\mathrm{Ha}=$ role expansion agreement is associated with industry type.

\section{Results}

Frequencies: There were 64 participants (57\%) that agreed with the expansion of the safety professional's role into security functions as indicated in Table 1 . There were 25 participants (23\%) that did not agree with the expansion of the safety professional's role into security as indicated in Table 1 . There were $20 \%(N=22)$ of respondents that neither agreed or disagreed with role expansion, rather wrote the word "depends" in the openended question that asked "why do you agree or disagree".

Forty and a half percent $(N=45)$ of the participants were from the manufacturing industry, 40.5\% $(N=45)$ were from the construction industry and 19\% $(N=18)$ are from the oil and gas industry. There was no significant relationship found between industry type and role expansion agreement $\left[\chi^{2}(4, N=111)=1.71, p=0.79\right]$; resulting in a failure to reject the null hypothesis (see Table 2).

\subsection{Agree with Role Expansion into Security Functions.}

There were 64 participants (57\%) that agree with the expansion of the safety professional's role into security. When asked "why”, participants responded with three over-arching categories: “obvious overlap with current safety role" $(N=38)$, "pro generalist” $(N=10)$, meaning additional responsibilities adds value to the role and offers another skill set, and "yes, if appropriate education and resources are granted" $(N=8)$. Frequency information for these categories are provided in Table 3. Examples of responses coded as "obvious overlap" with current safety role include: "Safety is not limited to personal safety but has always had aspects of site and physical safety in it. There is a natural progression to security," "Safety, Env and Security are inter-related in many aspects. Joining of forces seems to be cost effective," "Everything is all inter-related. Adding Facilities pushed me into a security role but even before that I was involved in many aspects regarding chemical security, workplace violence, emergency response and scene control to name a few. So yes it is appropriate," and "I feel that the expansion into Security makes sense. Security of a facility has a direct impact on personal safety and is related to programs such as emergency preparedness (such as bomb threats, workplace violence, etc.). These two areas 
Table 1. Descriptive Statistics for the question: “do you agree with expansion of the safety role into the security function?”

\begin{tabular}{ccc}
\hline Variable & Frequency (N) & Percent (\%) \\
\hline Respondents that answered "Yes" & 64 & $57 \%$ \\
Respondents that answered “No" & 25 & $23 \%$ \\
"Missing & 22 & $20 \%$ \\
Total & 111 & $100 \%$ \\
\hline
\end{tabular}

*Respondents that did not answer yes or no, but wrote “depends” on open-ended question.

Table 2. Industry type by role expansion into security cross tabulation.

\begin{tabular}{|c|c|c|c|c|c|c|}
\hline & & & \multicolumn{3}{|c|}{ Role Expansion into Security } & \multirow[b]{2}{*}{ Total } \\
\hline & & & Missing & Agree with role expansion & Do not agree with role expansion & \\
\hline \multirow{6}{*}{ Industry Type } & \multirow{2}{*}{ Manufacturing } & Count & 9 & 27 & 9 & 45 \\
\hline & & Expected Count & 8.9 & 25.9 & 10.1 & 45.0 \\
\hline & \multirow{2}{*}{ Construction } & Count & 10 & 23 & 12 & 45 \\
\hline & & Expected Count & 8.9 & 25.9 & 10 & 45.0 \\
\hline & \multirow{2}{*}{ Oil and Gas } & Count & 3 & 14 & 4 & 21 \\
\hline & & Expected Count & 4.2 & 12.1 & 4.7 & 21.0 \\
\hline \multirow{2}{*}{ Total } & & Count & 22 & 64 & 25 & 111 \\
\hline & & Expected Count & 22.0 & 64.0 & 25.0 & 111.0 \\
\hline
\end{tabular}

Table 3. Descriptive statistics for the reasons participants answered "YES” for expansion into security functions.

\begin{tabular}{ccc}
\hline Variable & Frequency $(\mathrm{N})$ & Percent $(\%)$ \\
\hline Obvious Overlap & 38 & 59 \\
Pro-generalist viewpoint, expansion = job security & 10 & 16 \\
If appropriate education and resources are granted & 8 & 12.5 \\
Missing & 8 & 12.5 \\
Total & 64 & 100 \\
\hline
\end{tabular}

seem to mesh well in my experience.” Examples of response coded “pro-generalist” include: "We must always be adding value and if we can do more, then we become more valuable," "One cannot specialize and be ensured of future work. Security has become much more important now, even if security is contracted out the function is overseen by the Safety Dept," "They all overlap each other and if we pigeon hole ourselves strictly to safety the demand for us is very narrow," and "There are synergies in these roles, and in our industry all are doing more with less. I have security now at my request, but it also makes managing contractor safety easier because the guards report to me for all functions." Examples of responses coded "yes, if appropriate education and resources are granted" include: "Expansion can be appropriate if the company is willing to provide the necessary training. I don’t believe the average safety professional has the background initially to cover multiple roles,” "Yes, but my recent thrust into a larger role with Security reminded me that this was not an emphasis during college or any previous workplaces”, and “Yes, I agree with the expansion; however, I don't agree with the methods. Environment and security do not simply fall in-line with what the typical Health \& Safety professional's knowledge base is. Training must be provided or additional resources are necessary”.

\subsection{Do Not Agree with Role Expansion into Security Functions}

There were 25 participants (23\%) that did not agree with the expansion of the safety professional's role into security. When asked "why”, participants responded with five over-arching categories: "separate discipline” ( $N=$ $15)$, "not educated, do not have the skill set" $(N=3)$, “distraction to primary safety role" $(N=3)$, "role overload" $(N=2)$, and "cop persona” $(N=2)$. Frequency information for these categories are provided in Table 4 . Exam- 
Table 4. Descriptive statistics for the reasons participants answered "NO" for expansion into the security function.

\begin{tabular}{ccc}
\hline Variable & Frequency (N) & Percent (\%) \\
\hline Separate Discipline & 15 & 60 \\
Distraction to primary safety role & 3 & 12 \\
Not educated, do not have the skill set & 3 & 12 \\
Role Overload & 2 & 8 \\
Cop Persona & 2 & 0 \\
Missing & 0 & 100 \\
Total & 25 & 8 \\
\hline
\end{tabular}

ples of responses coded "separate discipline" include: "I would not agree to expand into security as it is a separate and unrelated field," "no, security is a stand alone issue becoming more complex and time consuming, especially for Global operating companies," "No. I consider that safety is a career and job all by itself. Safety and security are not good partners as they do not complement each other in any way," and "In my opinion Security is it's own entity and is a different discipline." Examples of responses coded "distraction to primary safety role" include: "with role expansion you no longer become a practitioner and you get a peanut butter spread of experience but nothing real deep in any one area. The safety profession is becoming so wide it is losing its expertise and hands on experience to be credible," "No I don't agree, if the safety pro stays focused on eliminating injury rather than other distractions the safety pro and the organization benefit," and "No, I believe the safety role should remain specific to safety. Individuals who have multiple roles/responsibilities often find themselves unable to perform any one role as effectively as they feel they should. Often times performance morphs into a role of "Do what you have to do to get by and move on". Quality level suffers," Examples of responses coded "Not educated, do not have skill set" include: "Most safety professionals are ill-equipped either by training, knowledge or temperament to assume broader roles within their organizations" and "many people may have this in their title but not the qualifications necessary to effectively manage the additional roles." Examples of response coded "role overload" include: "no, I have enough to worry about as it is," and "no, I am trying to narrow my focus and avoid mission creep". Examples of responses coded "cop persona" include: "Pairing security with H\&S can give the perception that H\&S is also still a "policing function" and "Expansion into the security field is not appropriate because of the enforcement requirements. Safety professionals do not need to be known as cops also.”

\subsection{Depends}

There were $20 \%(N=22)$ of respondents that neither agreed or disagreed with role expansion, rather wrote the word "depends" in the open-ended question that asked "why do you agree or disagree". In expanding upon this answer, respondents most commonly wrote that it depends on complexity and size of the company $(N=5)$, depends whether resources such as time, employee to safety professional ratio is reasonable, and if additional training are available $(N=8)$, depends on the overall reporting structure or management style of the organization $(N=5)$ and lastly depends on industry type $(N=4)$.

\section{Discussion}

The majority of participants agree with the expansion (57\%), however it was indicated in previous studies that additional roles can increase the level of role conflict in safety professionals. Regardless of the increased stress that additional roles bring to safety professionals, the majority still agree with expansion into security. In addition, there was no significant relationship found between industry type and role expansion agreement suggesting the growth trend or willingness to perform security functions is consistent across all industries. Considering that the majority of safety professionals in this study agree with the expansion and that $25 \%$ of safety professionals are currently performing security functions in manufacturing, it is obligatory to examine the education required to perform these additional roles.

It is important for the general safety practitioner to have a working knowledge of security. Many safety professionals are willing to accept an expanded role, but do not currently possess the skill set needed to move for- 
ward in that direction. Although there may be several ways in which to make this determination, one approach is to examine the coursework required within occupational safety degrees. There are currently 14 occupational safety and health programs that are listed as being accredited [8]. A review of the coursework and program requirements listed on the website for each program indicated that 2 programs have security-related coursework on a list of possible electives (non-mandated courses), the three courses are titled: Introduction to Criminal Justice, Communication and Conflict, and Threat and Vulnerability Assessment and Management. There were no programs that currently require a course with "security" in the title as part of the degree program. However, a more thorough review should be conducted since elements of the security function could be housed within the courses and just not listed as part of the course title.

It may be difficult for an occupational safety program to justify an entire course on security, however there are several options to consider. One option is to incorporate security elements into existing coursework. Modules on conflict resolution, homeland security, workplace violence, and managing lock down or shelter in place scenarios would serve as starting point. In developing these modules, reaching out to organizations for assistance can be productive. Jeff Schoepf, a Certified Protection Professional (CPP) and the Certification Coordinator at the ASIS International Pittsburgh chapter, explained that ASIS offers a multitude of educational information and is available to the public upon request (personal communication, March, 18, 2015). ASIS offers webinars, conferences, books, and classes that can be accessed by non-members for a fee. Interested parties may also attend a chapter meeting by contacting their local chapter, via www.asisonline.org for meeting dates and times.

Additional resources include accessing information from the Department of Homeland Security (DHS). Not only does the DHS help protect and secure our national assets, they are concerned with the American presence overseas as well. For that reason they are very important to US based companies doing business or manufacturing in other countries and offer educational material on their website. In addition, FEMA offers online independent study courses and certifications that are related to disaster management. Many of these courses are based on fundamental safety and security training and it can be applied to overall security and safety at a facility. Additional information on the FEMA courses can be obtained at http://training.fema.gov/is/. Individual security companies offer education material as well. Lastly, using established professional organizations and their associated social media is also a resource.

Implications to the security function include the streamlining of managing risk within the safety role, both nationally and abroad. When asking a safety professional to describe a typical loss, he or she may suggest a fatality or accident. When a security professional is asked the same question he/she may say a breach of entry through a guarded gate, a theft, or a workplace shooting. A third party may say a loss is a loss regardless of where the box is located on the org chart and that the associated risks must be managed to prevent the loss. Managing the risk to prevent the loss is the key and the common denominator between safety and security. In terms of global implications, many organizations have been able to streamline efforts through the use of safety, environmental and quality management system correspondences [9]. The pending ISO 45001 Occupational Health and Safety management system slated for release in October, 2016 is a risk-based framework [10] [11]. Considering the safety role and security role are both risk-based, it could offer potential pathways in which to merge functions.

\section{Limitations}

Limitations of this study include sample size of each individual industry type and lack of additional descriptor variables such as industry size, complexity, and safety to employee ratio. In addition, it is possible that each safety professional may define or perceive "security" roles or functions differently, a common definition of the security role should be provided when creating a new survey or inventory. It would also be of importance to consider the percentage of time dedicated to the security functions.

\section{Conclusion}

Safety and security have a lot of similar duties, history, problems, and goals. Safety professionals are seeing an increase in responsibilities relating to security. Previous studies indicate that $25 \%$ of current practicing safety professionals include security in their job description; however there are no accredited occupational safety and health programs that require coursework on security. To properly address the gap between the current training that is offered to our formally educated professionals, it is important that we look to other sources. As part of our ethical obligations we are to be aware of our limitations and not reach beyond our skill set. In order to meet the 
demands of employers, safety professionals may need to reach out to other sources to expand our training. Although role expansion can increase role conflict and stress [5], the majority of participants (57\%) in this study agree with role expansion into security. Additional research in this area is merited to discern if the addition of security function to the safety professional is contributing to role overload. Additional variables of importance to include in a future study on role overload is to clearly identify how participants are defining their security function, quantify how many separate roles (i.e. environmental, quality) they are performing, the size of the company, and the number of employees the safety professional is supporting in their current role. In addition, a study on the perceptions from traditional security personnel on "role creep" of safety professionals in to their roles would be warranted.

\section{References}

[1] ANSI/ASSE Z590.2-2003 Standard (2015) Criteria for Establishing the Scope and Functions of the Professional Safety Position. http://www.safetybok.org/resources/criteria_for_establishing_the_scope_and_functions_of_the_professional_safety_po $\underline{\underline{\text { sition/ }}}$

[2] BSCP (2015) The Safety Professional Today. http://www.bcsp.org/SH-E-Practice

[3] ASIS (2015) Security Glossary. https://www.asisonline.org/Membership/Library/Security-Glossary/Pages/Security-Glossary-A.aspx

[4] ASIS (2015) About ASIS. https://www.asisonline.org/About-ASIS/Pages/default.aspx

[5] Minnick, W.D. (2012) Organizational and Personal Characteristics That Influence Role Conflict and Role Ambiguity in the Safety Professional. Doctoral Dissertation.

[6] ASSE (2015) About ASSE. http://www.asse.org/about/

[7] Brown, S.P., Jones, E. and Leigh, T.W. (2005) The Attenuating Effect of Role Overload on Relationships Linking SelfEfficacy and Goal Level to Work Performance. Journal of Applied Psychology, 90, 972. http://dx.doi.org/10.1037/0021-9010.90.5.972

[8] ASSE (2015) 2014-2015 Safety-Related Programs Accredited by ABET. http://www.asse.org/assets/1/7/2014-2015_Safety-Related_Programs_Accredited_by_ABET.pdf

[9] BSI (2007) BS OHSAS 18001:2007: Occupational Health and Safety Management Systems-Requirements.

[10] BSI (2015) ISO 45001: New International Standard for Occupational Health \& Safety Management Systems. http://www.bsigroup.com/en-US/OHSAS-18001-Occupational-Health-and-Safety/ISO-45001/

[11] ISO (2015) ISO 45001: Briefing Notes. http://www.iso.org/iso/iso_45001_briefing_note.pdf 